\title{
O ritmo do ano litúrgico e a escolha das leituras bíblicas na celebração da eucaristia dominical
}

\author{
The rhythm of the liturgical year and the choice of biblical \\ readings in the celebration of the Sunday Eucharist
}

Vitor Gino Finelon

\section{Resumo}

A teologia litúrgica reconhece o tempo como um sacramento. Os ciclos e os ritmos do tempo - diário, semanal e anual - são preenchidos pela anamnese dos eventos soteriológicos e pela epiclese da salvação no "hoje". Desta forma, o ano litúrgico é vivido como um grande memorial do mistério pascal de Cristo. Dentro desse contexto, a Liturgia da Palavra, cuja parte fundamental está na proclamação das leituras bíblicas, goza de importância radical para esta experiência memorial. Assim sendo, os liturgistas usaram os princípios teológicos de harmonização dos textos e de subordinação ao tempo litúrgico para organizar as leituras dispostas no lecionário dominical da celebração eucarística. A análise destes dois princípios e das suas relações possibilitam um entendimento das escolhas das leituras bíblicas do lecionário dominical e dos seus contatos teológicos com o ano litúrgico.

Palavras-chaves: Ano litúrgico. Lecionário dominical. Celebração Eucarística.

\begin{abstract}
Liturgical theology recognizes the time as a sacrament. The cycles and the rhythms of the time - days, weeks, years - are fulfilled by the anamnesis of the soteriological events and by the epiclesis of the salvation in the "today". In this way, the liturgical year is lived as a great memorial of paschal mystery of Christ. Inside of this scenario, the liturgy of the word, whose fundamental part is in the proclamation of biblical readings, possesses radical importance for this
\end{abstract}


memorial experience. Therefore, in organizing the Sunday readings in the lectionary liturgists used the theological principles of harmonization between texts and of subordination of the liturgical times. The analyses of these two principles and their relationships provides an understanding of the choices of biblical texts from de lectionary for Sunday and of their theological context within the liturgical year.

Keywords: Liturgical Year. Lectionary for Sunday. Eucharistic Celebration.

\section{Introdução}

Nosso artigo pretende expor, em linhas gerais, a relação existente entre o ano litúrgico e a seleção das leituras bíblicas da eucaristia dominical seguindo o culto católico. Para isso, desenvolveremos a compreensão teológica do ano litúrgico como lugar da celebração sacramental do mistério pascal de Cristo; em seguida, as razões da escolha dos formulários do lecionário dominical e, por fim, escolheremos alguns exemplos da articulação entre o tempo litúrgico e as leituras bíblicas, em consonância com os critérios de elaboração do lecionário dominical - o da harmonização e o da subordinação. Por fim, ainda, acreditamos ser importante sugerir algumas intuições pastorais decorrentes do desenvolvimento da temática em consonância com os desafios da igreja no Brasil.

\section{O ritmo do ano litúrgico}

A consciência místico-espiritual da igreja reconhece e acolhe a sacralidade do tempo. De fato, desde os tempos apostólicos até a afirmação do último calendário litúrgico no pós-concílio, o entendimento e a vivência do tempo como uma realidade penetrada e consagrada pelo Mistério Pascal de Cristo vêm se concretizando e encontrando uma envergadura considerável como um sacramental do evento criacional, salvífico e escatológico. Hoje, a celebração e a espiritualidade cristã católica manifestam, no ano litúrgico, "a memória sagrada da obra de salvação do seu divino Esposo". ${ }^{1}$

${ }^{1} \mathrm{SC} 102$. 


\subsection{Das cosmogonias para o memorial}

O fundamento antropológico da experiência do tempo permite apontar uma tríplice compreensão de tal fenômeno: uma cósmica, outra psicológica e, ainda, uma religiosa. O tempo cósmico é aquele categorizado pela física através do movimento dos astros e das coisas - e mensurado pela matemática em segundos, minutos, tempos, dias, meses, anos etc. O tempo psicológico, por sua vez, está ligado com a autoconsciência humana das vicissitudes de sua existência, permitindo percepções diferentes daquelas do arco temporal cósmico. Por fim, o tempo religioso é marcado pela comunhão com a esfera do divino quando, na tessitura dos movimentos cósmicos e nas vivências do tempo psicológico, se manifesta o numinoso diante do homem. ${ }^{2}$

A experiência deste tempo religioso nas manifestações primitivas se relaciona com o tempo cósmico. Os movimentos dos astros e as condições sazonais eram compreendidos como uma repetição cíclica de um tempo primordial. As narrativas deste momento inicial, denominadas como cosmogonias, contavam como os episódios da vida de uma divindade (ou mesmo de um panteão) originou ou influenciou certa condição temporal. $\mathrm{O}$ homem religioso, no seu culto, procurava reviver o tempo primordial a fim de vencer os dramas ameaçadores do presente. $^{3}$

A revelação judaico-cristã legou uma nova compreensão para a categoria de tempo. A espiritualidade de Israel transformou as festas religiosas de cunho agrário e pastoril (baseadas em cosmogonias) no culto memorial das ações efetivas de Javé na história, como Deus libertador, salvador e criador (Ex 12,14: "Este dia será para vós um memorial perpétuo"). Por conseguinte, o tempo sagrado bíblico difere do tempo religioso primitivo porque não se volta para um momento primordial de equilíbrio, mas relembra as ações concretas de Deus na história. Desta forma, Israel se afasta dos cultos cosmogônicos e inaugura a liturgia memorial. O tempo bíblico marca uma linearidade da história, abrindo o presente para o futuro diante da experiência consolidada do passado. ${ }^{4}$

\footnotetext{
${ }^{2}$ ELIADE, M., O sagrado e o profano, p. 42-45.

${ }^{3}$ LÓPEZ MARTÍN, J., Tempo Sagrado, Tempo Litúrgico e Mistério de Cristo, p. 31-65.

${ }^{4}$ NEUNHEUSER, B., Memorial, p. 723-736.
} 


\subsection{O tempo como sacramental do Mistério Pascal de Cristo}

A espiritualidade de Israel, com a inauguração do memorial, alavancou as bases do culto cristão. ${ }^{5}$ É importante destacar que Jesus celebrou os eventos salvíficos no culto israelita: na sua oração pessoal (Lc 6,2), no culto sinagogal (Lc 4,16), nas peregrinações a Jerusalém (Jo 2,13), nas grandes festas (Jo 10,22), no templo (Lc 21,2). A vida do Filho de Deus feito homem se enquadra dentro da marca da espiritualidade de seu povo, se caracterizando, então, pelo memorial das maravilhas salvíficas de Deus. Dentro das categorias da mística judaica, Jesus inaugura o memorial cristão.

$\mathrm{Na}$ economia neotestamentária, o zênite da salvação cristã se manifesta no evento da morte e ressurreição de Jesus Cristo. Assim, o conteúdo cultual do antigo Israel - o memorial da libertação do Egito - se plenificou na celebração anamnética do mistério pascal de Cristo - memorial da libertação do pecado e da morte. No mandato deixado por Jesus, na última ceia, por motivo da instituição da eucaristia, encontramos uma das dimensões centrais da santificação do tempo para o cristianismo: "Fazei isto em memória de mim" (Lc 22,19; 1Cor 11,24).

O tempo religioso cristão - kairótico - é encarado como a penetração da salvação no tempo cronológico através da memória do mistério pascal de Cristo. O tempo litúrgico é preenchido da salvação e aberto ao louvor e à oração. Os ritmos desse tempo anamnético e epliclético se encontram com os do tempo cósmico: as horas, os dias, as semanas, o ano. Desta forma, se fala de um ciclo diário, semanal e anual no qual a igreja se reúne para fazer a memória e a presentificação da salvação.

O ciclo diário se estabelece com a celebração da eucaristia e com a recitação da liturgia das horas. A missa é como o centro e a liturgia das horas como seu prolongamento. ${ }^{6} \mathrm{Na}$ liturgia das horas se faz a memória dos eventos

\footnotetext{
${ }^{5}$ Assim se expressa o magistério na Dies Domini 75: "Sendo o domingo a Páscoa semanal que evoca e torna presente o dia em que Cristo ressuscitou dos mortos, ele é também o dia que revela o sentido do tempo. Não tem qualquer afinidade com os ciclos cósmicos que, segundo a religião natural e a cultura humana, poderiam ritmar o tempo, fazendo crer talvez ao mito do eterno retorno. O domingo cristão é diverso! Nascendo da Ressurreição, ele sulca os tempos do homem, os meses, os anos, os séculos como uma seta lançada que os atravessa, orientando-os para a meta da segunda vinda de Cristo. O domingo prefigura o dia final, o da Parusia, já antecipada de algum modo pela glória de Cristo no acontecimento da Ressurreição".

6 "A liturgia das horas alarga aos diferentes momentos do dia o louvor e ação de graças, a memória dos mistérios da salvação, as súplicas, o antegozo da glória celeste, contidos no mistério
} 
salvíficos acontecidos correspondentes as horas celebradas: manhã (a criação e a ressurreição), às $9 \mathrm{~h}$ (a condenação de Cristo e a descida do Espírito sobre os discípulos no cenáculo), às $12 \mathrm{~h}$ (a crucifixão e a ascensão), às $15 \mathrm{~h}$ (a morte de Cristo e o testemunho da igreja), ao entardecer (a obra da redenção e a instituição da eucaristia) e à noite (a morte). ${ }^{7}$

O ciclo semanal surge com a celebração da eucaristia dominical e com a vivência do domingo como o dia do Senhor. O domingo possui uma carga anamnética primordial entre os outros dias da semana porque nele se concentra o aspecto criacional, salvífico e escatológico, relacionado com os grandes eventos soteriológicos: a Criação, a Ressurreição, o Pentecostes e a Parusia. ${ }^{8}$

O ciclo anual, por sua vez, formado pelo diário e o semanal, se caracteriza como uma grande memória do mistério pascal de Cristo. Por isso, sua divisão corresponde aos principais mistérios da vida do Senhor. O subciclo da manifestação do Senhor comporta a promessa veterotestamentária da vinda do Messias (tempo do advento), seu nascimento (tempo do natal) e sua manifestação a Israel e ao mundo (epifania). O subciclo da Páscoa recorda a vivência de Jesus no deserto (tempo da quaresma), sua paixão, morte e ressurreição (Tríduo Pascal e domingo de Páscoa), suas aparições aos discípulos (tempo pascal), sua subida aos céus (ascensão) e a vinda do Espírito Santo (pentecostes). O tempo comum ou ordinário se liga aos eventos do ministério da vida do Senhor, desde o seu batismo até seu reino final escatológico.

Apesar de apresentar contatos com o tempo cósmico, o ano litúrgico não se resume a ciclos e ritmos. Ele é parte integrante da celebração eclesial, pois é um sacramental para a memória e a vivência do mistério pascal de Cristo. Isso quer dizer que na celebração o evento passado salvífico atinge o hoje

eucarístico, centro e vértice de toda a vida da comunidade cristã" (Instrução Geral a Liturgia das Horas 12).

${ }^{7}$ BECKHAUSER, A., Liturgia das horas, p. 42-43.

${ }^{8}$ Dies Domini 59 afirma que "no dia do Senhor, que o Antigo Testamento - como foi dito liga com a obra da criação (Gn 2,1-3; Ex 20,8-11) e do êxodo (Dt 5,12-15), o cristão é chamado a anunciar a nova criação e a nova aliança, realizadas no mistério pascal de Cristo. A celebração da criação, longe de ser anulada, é aprofundada em perspectiva cristocêntrica, ou seja, à luz do desígnio divino de recapitular em Cristo todas as coisas que há no Céu e na Terra $(\mathrm{Ef} 1,10)$. E ao memorial da libertação realizada no êxodo, é-lhe conferido também sentido pleno, tornando-se memorial da redenção universal operada por Cristo morto e ressuscitado. Portanto, mais do que uma substituição do sábado, o domingo constitui a sua perfeita realização e, de certa forma, o seu desenvolvimento e plena expressão no caminho da história da salvação, que tem o seu ponto culminante em Cristo". 
comemorativo. Assim, o próprio Senhor atua no seu corpo místico quando este se reúne para fazer a memória dos eventos salvíficos, e estes eventos se presentificam, comunicando a sua graça no hoje.

Sobre a natureza do ano litúrgico, citamos a compreensão de um dos expoentes do Movimento Litúrgico responsável pela recuperação e pela fundamentação teológica do tema da sacralidade do tempo:

Esta vida do Cristo-Senhor, esse itinerário gigantesco que vai do seio da Virgem e da manjedoura até o trono da divina majestade: eis o mistério que nos cabe viver no ano litúrgico. Trata-se de comemorar os grandes feitos de nossa salvação, de evocá-los e de nos apropriarmos deles. Não basta seguir e contemplar com um sentido de suave piedade os detalhes da vida terrestre do Senhor - um não batizado poderá fazê-lo -; como cristãos e católicos, devemos celebrar o mistério de Cristo. ${ }^{9}$

\section{O ano litúrgico e as leituras da eucaristia dominical}

A memória do mistério pascal do Senhor no transcurso do ano se manifesta nas celebrações concretas. Em todas essas celebrações, a liturgia da palavra é parte constitutiva, integrante e essencial. Por isso, precisamos compreender a relação teológica entre o ano litúrgico e a proclamação da palavra de Deus para chegarmos a entender os critérios de escolha das leituras bíblicas pertencentes ao lecionário dominical para a celebração da missa. ${ }^{10}$

\subsection{De Jesus à igreja: leitores e hermeneutas da Escritura}

A narrativa de Jesus entrando na sinagoga, recebendo e proclamando a passagem do profeta Isaías e, por fim, atualizando-a no hoje salvífico se tornou o fundamento escriturístico da liturgia da Palavra. Ora, o ofício sinagogal caracterizava-se pela memória das maravilhas operadas por Deus através da leitura-escuta, da interpretação e da oração dos textos sagrados. O evangelista Lucas propõe um quadro paradigmático de atualização da liturgia da palavra de

\footnotetext{
${ }^{9}$ CASEL, O., O mistério do culto no cristianismo, p. 89.

10 “As leituras tiradas da Sagrada Escritura, com os cânticos que se intercalam, constituem a parte principal da liturgia da palavra; a homilia, a profissão de fé e a oração universal ou oração dos fiéis, a desenvolvem e concluem" (OLM 11). A liturgia da palavra deve ser compreendida em seus elementos constitutivos: proclamação, homilia, profissão de fé e oração, sendo que a proclamação goza de caráter principal.
} 
Israel para a cristã, na qual a palavra escrita - os rolos sagrados - se visibiliza na palavra encarnada - Jesus. ${ }^{11}$

É possível estabelecer um quadro análogo entre a experiência com a palavra feita por Jesus e pela igreja, na qual a segunda realidade tem a primeira como fonte e paradigma. Tudo isto porque os espaços, os gestos e as palavras que compõem a liturgia da palavra são sacramentais e, por um lado, rememoram o ministério querigmático do Senhor e, por outro, tornam-se instrumento para que o mesmo anúncio ressoe para a assembleia e o mundo:

\begin{tabular}{|c|c|}
\hline Jesus na sinagoga de Nazaré & A liturgia da Palavra \\
\hline Entrou em dia de sábado & O domingo \\
\hline Na sinagoga & O templo e o ambão \\
\hline Levantou-se para fazer a leitura & A procissão para o ambão \\
\hline Foi-lhe entregue o rolo do profeta Isaías & O lecionário e o evangeliário \\
\hline $\begin{array}{c}\text { Desenrolou-o e encontrou o trecho } \\
\text { onde estava escrito }\end{array}$ & A perícope selecionada \\
\hline Todos na sinagoga tinham os olhos nele & A postura da assembleia \\
\hline Então começou a dizer-lhes & A proclamação e a homilia \\
\hline Todos testemunhavam a seu respeito & $\begin{array}{c}\text { O acolhimentâncio Palavra na vida } \\
\text { Profissão de fé } \\
\text { Oração dos fiéis }\end{array}$ \\
\hline
\end{tabular}

A liturgia da palavra, presente, atualmente, na celebração de todos os sacramentos e sacramentais, estrutura-se por meio de espaços, ações e palavras. Os seus espaços centrais são o altar (onde repousa o livro dos Evangelhos, revelando a íntima ligação entre palavra e eucaristia) e o ambão (lugar próprio para a proclamação das leituras). Suas ações se visibilizam no estar de pé, no tomar, no abrir, no incensar, no ler, no silenciar, no beijar e no fechar o livro. As palavras estão na proclamação e no canto do texto sagrado.

Por sua vez, o contato com a palavra não se esgota na celebração da liturgia. Ele excede e transborda para vida de oração do fiel. A leitura orante é o modo como os batizados prolongam a escuta da liturgia da palavra na vida. O objetivo final é o acolhimento da voz do Ressuscitado pela comunidade de

\footnotetext{
11 "Jesus dá início a seu ministério de pregação com aquela leitura, de modo que seu primeiro ato ministerial é um ato cultual, seu primeiro gesto público é um gesto litúrgico”. BOSELLI, G., O sentido espiritual da liturgia, p. 50.
} 
fé e pelos discípulos e seu testemunho no mundo. ${ }^{12}$ Neste sentido, podemos também traçar os pontos de contato entre liturgia da palavra e leitura orante:

\begin{tabular}{|c|c|}
\hline A liturgia da Palavra & Leitura orante \\
\hline O domingo & Diariamente \\
\hline Comunitária & Comunitária e pessoal \\
\hline A procissão para o ambão & \multirow{2}{*}{ Leitura } \\
\hline O lecionário e o evangeliário & \\
\hline A perícope selecionada & Meditação \\
\hline A postura da assembleia & \\
\hline A homilia & Oração e contemplação \\
\hline O acolhimento da Palavra na vida & \\
Silêncio & \\
Profissão de fé & \\
Oração dos fiéis & \\
\hline
\end{tabular}

\subsection{A igreja prepara a mesa da Palavra para os seus fiéis}

A igreja, consciente de sua missão de mediadora entre a voz do Ressuscitado e seu povo santo reunido, entende que a Escritura Sagrada deve ser franqueada na celebração litúrgica - "prepare-se para os fiéis, com maior abundância, a mesa da Palavra de Deus: abram-se mais largamente os tesouros da Bíblia, de modo que, dentro de um período de tempo estabelecido, sejam lidas ao povo as partes mais importantes da Sagrada Escritura" ${ }^{13}$ Desta forma, ela assumiu para si a tarefa de abrir e ler as partes mais importantes da Escritura na celebração do culto.

Esta abertura segue certos critérios apontados no Ordo Lectionum Missae, em especial dos parágrafos 64 até o 91. Para nosso tema - a relação

\footnotetext{
${ }^{12}$ A Verbum Domini 86 trata dessa relação entre liturgia da Palavra e lectio divina de maneira muito própria: "Por isso, na leitura orante da Sagrada Escritura, o lugar privilegiado é a Liturgia, particularmente a Eucaristia, na qual, ao celebrar o Corpo e o Sangue de Cristo no Sacramento, se atualiza no meio de nós a própria Palavra. Em certo sentido, a leitura orante pessoal e comunitária deve ser vivida sempre em relação com a celebração eucarística. Assim como a adoração eucarística prepara, acompanha e prolonga a liturgia eucarística, assim também a leitura orante pessoal e comunitária prepara, acompanha e aprofunda o que a Igreja celebra com a proclamação da Palavra no âmbito litúrgico. Colocando em relação tão estreita lectio e liturgia, podem-se identificar melhor os critérios que devem guiar esta leitura no contexto da pastoral e da vida espiritual do Povo de Deus".

${ }^{13}$ SC 51.
} 
entre o ano litúrgico e a escolha das leituras, a nossa atenção deve recair no parágrafo 67. Segue abaixo a transcrição do parágrafo referido para fazermos uma análise dos seus detalhes mais pertinentes ao nosso estudo:

A melhor composição harmônica entre as leituras do Antigo e do Novo Testamento tem lugar quando a própria Escritura a insinua, isto é, naqueles casos em que os ensinamentos e fatos expostos nos textos do Novo Testamento têm uma relação mais ou menos explícita com os ensinamentos e fatos do Antigo Testamento. No presente Elenco das Leituras da Missa, os textos do Antigo Testamento foram selecionados principalmente por sua congruência com os textos do Novo Testamento, especialmente com o Evangelho que se lê na mesma missa. No tempo do Advento, Quaresma e Páscoa, isto é, naqueles tempos dotados de importância e características especiais, a composição entre os textos das leituras de cada missa baseia-se em princípios especiais. No entanto, nos domingos do Tempo Comum, que não têm uma característica peculiar, os textos da leitura das Epístolas e do Evangelho se distribuem segundo a ordem da leitura semicontínua, ao passo que a leitura do Antigo Testamento se compõe harmoniosamente com o Evangelho. ${ }^{14}$

Neste parágrafo, temos dois tipos de critérios: um geral, abrangendo qualquer período do ano litúrgico e outro específico voltado para os seus tempos fortes. Em relação aos critérios gerais, encontramos o da harmonização entre as leituras extraídas do Antigo e do Novo Testamento - é fato que os hagiógrafos neotestamentários se valeram de textos, de temas, de episódios e da teologia veterotestamentária e que esse recurso literário está testemunhado nos seus escritos. Por isso, um primeiro critério é estabelecer estes textos e apresentá-los nos formulários do lecionário. Em relação aos critérios específicos, encontramos que nos tempos do Advento, da Quaresma e da Páscoa, as leituras são escolhidas não só obedecendo a harmonização, mas relacionando-as com as características próprias de cada tempo. ${ }^{15}$

\footnotetext{
${ }^{14}$ OLM 67.

${ }^{15}$ Em relação aos elementos estruturais da liturgia da palavra, também eles vão receber influxo do ano litúrgico. Dessa forma a homilia e as preces, como nascem das leituras escolhidas, serão penetrados com elementos dos tempos litúrgicos. Essa articulação e dependência entre as leituras pode ser assim, brevemente, explicada: "a primeira leitura anuncia o Evangelho, o salmo remete à primeira leitura, a aclamação é o prefácio do Evangelho, a homilia e a oração universal garantem a unidade do conjunto". DEISS, L., A palavra de Deus celebrada, p. 20.
} 
Existe uma relação intrínseca entre ano litúrgico e a escolha das leituras para o lecionário dominical. De tal forma que nos chamados tempos fortes (Quaresma, Páscoa, Advento, Natal) encontramos as perícopes bíblicas relacionadas com os eventos da vida de Jesus correspondentes a eles, enquanto que no tempo comum, no ciclo de três anos, lemos os evangelhos de forma contínua e uma leitura do primeiro Testamento cuja relação episódica, temática ou textual se estabeleça explícita ou implicitamente. ${ }^{16}$

\section{Uma breve análise de alguns formulários do lecionário}

Agora que já nos munimos da teologia do ano litúrgico e percebemos o influxo dele na escolha das perícopes do lecionário dominical para a celebração eucarística, vamos nos deter em alguns exemplos. Escolheremos quatro exemplos: o primeiro, baseado no critério de harmonização explícita; o segundo, no de harmonização implícita; o terceiro, na junção entre harmonização e subordinação; e, o último, apenas no critério de subordinação.

Um exemplo de conjunto de leituras escolhido baseado no critério de harmonização explícita, achamos no vigésimo sétimo domingo do tempo comum do ano A. A primeira leitura é Is 5,1-7 na qual se apresenta o tema da vinha. O salmo 79 responde diretamente à primeira leitura visto que reza a Deus com a temática da vinha. No texto do Evangelho de Mt 21,33-43, Jesus conta uma parábola aos sumos sacerdotes e aos anciões do povo cujo tema também é o da vinha. Desta forma, as leituras se conectam de forma temática possibilitando uma interpretação tipológica: Israel com a vinha de Deus e a igreja nova arrendatária da vinha do Senhor.

No formulário de leituras disposto para o décimo quinto domingo do tempo comum do ano A, encontramos um exemplo do critério de harmonização implícita. A primeira leitura é tirada do profeta Is 55,10-11 cujo tema é a eficácia da palavra de Deus. O salmo responsorial, S1 64, apresenta a ordem cósmica sustentada por Deus. Como evangelho, temos Mt 13,1-23, no qual Jesus conta a parábola do semeador para uma multidão e depois explica aos seus discípulos o porquê do uso das palavras e o significado específico das parábolas. Embora, seja possível reconhecer um tema unificador entre as leituras - a palavra de Deus - não é possível fazer uma hermenêutica tipológica direta.

${ }^{16}$ ALDAZÁBAL, J., A mesa da Palavra I, p. 93. 
O ano litúrgico influencia na escolha das leituras e pode direcionar os critérios de harmonização dos textos. Vemos isso claramente, por exemplo, no elenco de leituras proposto para o quarto domingo do advento do ano A. A primeira leitura, Is 7,10-14, é a profecia do nascimento do Emanuel. O salmo 23 responde à leitura precedente tocando no tema da geração que busca a Deus. $\mathrm{O}$ evangelho é a narrativa mateana da origem de Jesus (Mt 1,18-24). O texto evangélico foi escolhido em função do tempo do advento a fim de mostrar os eventos preparatórios da primeira vinda do filho de Deus - critério temático do ano litúrgico. Ademais, o evangelho faz uma repetição textual explícita do oráculo da primeira leitura: "Eis que a virgem conceberá e dará à luz um menino. Ele será chamado Emanuel que significa Deus conosco" e possibilita uma leitura tipológica entre o primeiro nascimento ao qual a profecia se dirige e o nascimento do Senhor - critério da harmonização dos textos. Neste exemplo temos uma concordância dos princípios, tanto o da harmonização explícita dos textos do Antigo e do Novo Testamento quanto da subordinação temática ao ano litúrgico, revelando a beleza ímpar e o trabalho árduo na elaboração do lecionário dominical.

É possível perceber certos formulários nos quais o critério temático do ano litúrgico se sobressai ao da harmonização de textos. Um exemplo disso é o elenco de leituras oferecido para a celebração dominical no tempo da Quaresma do ano A. As primeiras leituras dos cinco domingos não dialogam com o evangelho, mas entre si. Elas pretendem ser um breve resumo da história da salvação em sua primeira aliança: Gn 2,7-9; 3,1-7 (a criação e a queda), Gn 12,1-4a (o chamado e as promessas a Abraão), Ex 17,3-7 (Moisés e a sede do povo no deserto), $1 \mathrm{Sm}$ 16,1b.6-7.10-13a (Davi é ungido rei de Israel), Ez 37,1214 (a promessa da efusão do Espírito de Deus). Os evangelhos também são escolhidos de forma temática, sem uma comunicação direta com a primeira leitura. No ano A, temos a narrativa da ida de Jesus para o deserto (Mt 4,1-11) e a transfiguração (Mt 17,1-9) tratando, respectivamente, da consagração quaresmal e da transformação interior. Nos demais domingos, a igreja propõe os formulários recuperados da prática da iniciação cristã da igreja dos Padres: a samaritana (Jo 4,5-42), o cego de nascença (Jo 9,1-41) e a ressurreição de Lázaro (Jo 11,1-45). Desta forma, temos um exemplo do influxo direto do ano litúrgico no elenco das leituras dominicais, sem a presença do critério de harmonização das leituras. 


\section{O tempo e a palavra na experiência místico-espiritual da igreja}

Todo esse desenvolvimento teológico sobre a relação entre tempo litúrgico e a palavra de Deus precisa se manifestar nas celebrações do povo de Deus. Ainda que os ritos estejam perpassados dessa teologia, as disposições dos celebrantes (ministros ordenados e leigos) carecem de uma formação mais qualificada para uma participação mais consciente, ativa e frutuosa. ${ }^{17}$ Contudo, esta formação não pode se reduzir apenas a conteúdos informativos, mas precisa chegar a experimentar a força vivificante de uma celebração cristã autêntica. Apesar de desejável, nada disso é fácil!

As perguntas seriam várias: como possibilitar ao povo de Deus acolher a sacralidade do tempo? De que modo favorecer a escuta para que a Palavra proclamada seja uma experiência de revelação do Ressuscitado? Por que a comunidade de fé ainda tem uma postura neutra, passiva e pouco frutuosa diante do mistério pascal de Cristo?

A necessária recuperação de uma teologia sacramental na qual, por um lado, as práticas celebrativas não se tornem ocasião para incentivo de uma consciência mágico-supersticiosa e distante da experiência de fé que motivava as primeiras comunidades cristãs na vivência radical do amor cristão ${ }^{18} \mathrm{e}$, por outro, que valorize a dimensão sacral do tempo consagrado pelo mistério pascal de Cristo dispondo a todos os fiéis os dias celebrativos em consonância com a concentração memorial das solenidades, festas, memórias e dias feriais.

A conversão da paróquia em "escola de leitores" onde a centralidade da espiritualidade bíblico-litúrgica se desenvolva, possibilitando que, de fato, o iniciado se torne um "leitor" capaz de se alimentar espiritualmente pela proclamação da Palavra no culto e pela lectio divina comunitária e individual. ${ }^{19}$ Dentro desta proposta, as formações bíblicas poderiam possibilitar uma leitura

\footnotetext{
${ }^{17} \mathrm{SC} 14$.

18 "Na Palavra e na Eucaristia, o cristão, nova criatura pelo Batismo, vive numa nova dimensão, a relação com Deus e com o próximo: a dimensão do amor como ágape". (CNBB, Doc. 100, 183).

${ }^{19}$ A CNBB no seu estudo sobre a nova paróquia apresenta esta relação entre liturgia e Palavra: “A liturgia é o lugar privilegiado para a Igreja escutar a voz do Senhor: "Considerando a Igreja como 'casa da Palavra', deve-se, antes de tudo, dar atenção à Liturgia sagrada, que constitui, efetivamente, o âmbito privilegiado onde Deus nos fala no momento presente da nossa vida: fala hoje ao seu povo, que escuta e responde. Cada cristão precisa encontrar-se pessoalmente com Jesus Cristo e fazer um ato de adesão total ao Senhor. A comunidade é assim a casa da iniciação à vida cristã. Igualmente, os Círculos Bíblicos e a prática da Leitura Orante da Palavra, na perspectiva da animação bíblica da pastoral, muito podem oferecer para que esse encontro se realize". (CNBB, Doc. 100, 180).
} 
escriturística em conformidade com a experiência litúrgica. De tal forma, que a formação não se reduza às informações sobre autoria, datação, local de composição, destinatários e estrutura literária do livro bíblico, mas se torne experiência real de comunicação entre Deus e o seu Povo.

Uma urgente catequese menos imbuída de uma linguagem dogmática e mais acessível e aberta às dúvidas e às necessidades do homem de hoje, bem como a redescoberta catequética da linguagem tipológica tão utilizada na igreja dos Padres, na qual se permitem analogias diretas entre o tempo bíblico e as vicissitudes hodiernas, poderia favorecer uma interpretação, sempre na linha dos grandes intérpretes da tradição eclesial, mais eficaz para as demandas humanas, espirituais e sociais atuais. ${ }^{20}$

\section{Conclusão}

A empenhativa tarefa da igreja de conduzir as pessoas ao mistério pascal de Cristo possui duas realidades sacramentais que se entrecruzam e se retroalimentam: o ano litúrgico e a palavra de Deus. Através delas, a celebração da palavra vai possibilitando que os fiéis tenham acesso ao rico tesouro da revelação cristã. Tempo e palavra são categorias teológicas cuja fecundidade ultrapassa a nossa compreensão.

O tempo litúrgico é um sacramental do mistério pascal de Cristo. No transcurso do dia, da semana e do ano, a igreja se ocupa na memória da obra salvífica, iniciada na criação e consumada no escathón. O tempo se abre para colocar os fiéis em contato com os eventos soteriológicos e dispensar a força da graça cristificante para eles. Assim, o tempo cronológico - sucessão de dias marcados pelo movimento cósmico - se torna tempo kairótico - penetração da salvação nos ciclos do tempo cósmico.

A celebração da Palavra de Deus é parte integrante e essencial da liturgia dos sacramentos e sacramentais. Por meio dela, os fiéis escutam ressoar a voz do Ressuscitado na proclamação das leituras, revelando, no hoje, o projeto salvífico do Pai e enviando o Espírito Santo para concretizá-lo por meio deles no mundo. Neste sentindo, o texto da Escritura e a sua proclamação na liturgia gozam de caráter instrumental para a experiência do mistério do Cristo com seu povo.

20 "Conforme o Papa, não bastam encontros com palestras que informam sobre diversos temas. É preciso promover um processo metodológico capaz de envolver as pessoas no saber, no fazer e no ser cristão. Há muita informação, mas falta formar discípulos missionários" (CNBB, Doc. $100,305)$. 
As passagens que compõem o elenco do lecionário dominical são escolhidas de acordo com dois critérios: a harmonização dos textos (explícita ou implícita) e a subordinação ao tema do tempo litúrgico correspondente. Desta forma, o elenco de leituras para cada domingo pode ser compreendido em quatro formulações possíveis: formulários com harmonização explícita, com harmonização implícita, com harmonização e adequação ao tempo litúrgico e apenas com adequação ao tempo litúrgico. Todo este quadro permite uma riqueza sem igual na apresentação dos temas teológicos para a celebração.

\section{Referências bibliográficas}

ALDAZÁBAL, J. A mesa da Palavra I: Elenco das leituras da missa. São Paulo: Paulinas, 2007.

BECKHAUSER, A. Liturgia das horas: Teologia e espiritualidade. Petrópolis: Vozes, 2010.

BENTO XVI, PP. Exortação Pós-sinodal Verbum Domini. Disponível em: $<$ http://w2.vatican.va/content/benedict-xvi/pt/apost_exhortations/documents/hf_benxvi_exh_20100930_verbum-domini.html>. Acesso em: 30 jul. 2018.

BÍBLIA de Jerusalém. São Paulo: Paulus, 2010.

BOSELLI, G. O sentido espiritual da liturgia. Brasília: CNBB, 2014.

CASEL, O. O mistério do culto no cristianismo. São Paulo: Loyola, 2009.

CONCÍLIO VATICANO II. Constituição Sacrossanctum Concilium. Disponível em: $<$ http://www.vatican.va/archive/hist councils/ii vatican council/documents/v atii_const_19631204_sacrosanctum-concilium_po.html $>$. Acesso em: 30 jul. 2018 .

CNBB. Comunidade de comunidades: uma nova paróquia. A conversão pastoral da paróquia. São Paulo: Paulinas, 2015. (Doc. 100).

CONGREGAÇÃO PARA O CULTO DIVINO. Elenco das leituras da Missa. São Paulo: Paulinas, 1994 (OLM).

CONGREGAÇÃO PARA O CULTO DIVINO. Instrução geral à Liturgia das Horas. São Paulo: Paulinas, 2010.

DEISS, L. A palavra de Deus celebrada: Teologia da celebração da palavra de Deus. Petrópolis: Vozes, 1998. 
ELIADE, M. O sagrado e o profano. São Paulo: Martins Fontes, 1992.

JOÃO PAUlO II, PP. Carta Apostólica Dies Domini. Disponível em: $<$ http://w2.vatican.va/content/john-paul-ii/pt/apost_letters/1998/documents/hf_jpii_apl_05071998_dies-domini.html $>$. Acesso em: 30 jul. 2018.

LÓPEZ MARTíN, J. Tempo Sagrado, Tempo Litúrgico e Mistério de Cristo. In: BOROBIO, D. (Org.). A celebração da Igreja. São Paulo: Loyola, 2000. p. 31-65. v.3.

NEUNHEUSER, B. Memorial. In: SARTORE, D.; TRIACCA, A. M. Dicionário de liturgia. São Paulo: Paulus, 2009. p. 725-736.

Vitor Gino Finelon

Doutorando em Teologia pela Pontifícia Universidade Católica do Rio de Janeiro Rio de Janeiro / RJ - Brasil E-mail: ginofinelon@gmail.com

Recebido em: $24 / 08 / 18$ Aprovado em: 02/11/18 